\title{
Detecting Abrupt Change of Streamflow at Lintong Station of Wei River
}

\author{
Jingjing Fan, ${ }^{1}$ Qiang Huang, ${ }^{1}$ Jianxia Chang, ${ }^{1}$ Dongyong Sun, ${ }^{2}$ and Shen Cui ${ }^{1}$ \\ ${ }^{1}$ Xi'an University of Technology, Xian 710048, China \\ ${ }^{2}$ Chang'an University, Xi'an 710054, China \\ Correspondence should be addressed to Qiang Huang; wresh@mail.xaut.edu.cn
}

Received 19 February 2013; Accepted 7 April 2013

Academic Editor: Yongping Li

Copyright (c) 2013 Jingjing Fan et al. This is an open access article distributed under the Creative Commons Attribution License, which permits unrestricted use, distribution, and reproduction in any medium, provided the original work is properly cited.

\begin{abstract}
According to abrupt diagnosis of runoff, two methods, that is, moving approximate entropy and moving permutation entropy, are used to analyse the abrupt year of the daily river runoff from 1961 to 2006 at Lintong station of Wei River in Loess Plateau. The runoff series are divided into 4 stages. With the analysis of hydrological characters of different stages, we find that there are abrupt changes at the three years 1972, 1983, and 2002. The result shows that moving approximate entropy and moving permutation entropy methods are useful tools for abrupt diagnosis of runoff. The attribution of abrupt change at the Lintong runoff series is primarily due to the reduced precipitation, increased water conservancy project, increased water consumption of industry and agriculture, significantly decreased groundwater table, and increased evaporation.
\end{abstract}

\section{Introduction}

Runoff is an important hydrological variable in the hydrological cycle. Climate change and human activities have the potential to cause significant changes in runoff behavior, and it is likely that one of the most serious consequences of global warming will be an increased frequency of extreme hydrological events due to changes in runoff patterns [13]. This trend is illustrated by the ongoing intensification of various hydrological components of the water cycle [46]. A detailed understanding of hydrological series and the factors that affect them is essential for the sustainable exploitation and use of water resources, disaster prevention, and the effective management of water conservation projects. Two types of change can be discerned in hydrological time series: continuous change and abrupt change. In a continuous change the parameter of interest varies smoothly, whereas an abrupt change involves a sudden jump from one value to a much greater or lower value. Methods for the identification and analysis of nonlinear (i.e., discontinuous) variation have been developed by researchers examining meteorological variation. These techniques have had a substantial impact on modern climatology [7], resulting in a much greater emphasis being placed on complexity, interactions between different components of the climate system, and nonlinear factors than was once the case. The identification of abrupt changes requires careful statistical analysis and is highly sensitive to both the time scale over which an event takes place and the length of the analyzed data series.

After the introduction of nonlinear methods, many scholars came to realize that climatic variation is driven by both internal and external forcing mechanisms, resulting in the development of dynamic techniques for the analysis of climate change. For example, a recent study on five temperature series gathered from meteorological stations within the Yangtze Delta used the concept of conditional entropy to test the commonality of the series' underlying dynamics [8]. Similarly, GIS data were used in conjunction with information entropy analysis to analyze the spatial and temporal variation in precipitation around the Chaobai River basin [9]. Pincus and coworkers developed the concept of approximate entropy as a tool for analyzing time series and studying system complexity [10]. This approach has been applied to identify abrupt climate change events and mutations in the series' structural dynamics [11]. Weiping et al. used approximate entropy analysis to investigate the spatial 
and temporal variation in climate data. Their studies demonstrated that approximate entropy analysis is an effective tool for highlighting structural changes in a system's dynamics [12]. Hou Wei and colleagues introduced the concept of permutation entropy and used it to analyze the variation in temperature data series for Northern China. By applying empirical mode decomposition to their results, they were able to demonstrate a close relationship between abrupt temperature changes and sunspot activity [13]. In this work, we used a similar approach to analyze the variation in runoff series for the Wei River basin.

\section{Methodology}

2.1. The Moving Approximate Entropy Test for Identifying Abrupt Changes. Some significant abrupt diagnosis methods of the basic concepts of probability and correlation analyses that are applicable in hydrologic engineering [14] are based on the linear theory and work with the system characteristics such as mean value and trend analysis. In physical sciences entropy relates macroscopic and microscopic aspects of nature and determines the behaviour of macroscopic systems in equilibrium [15]. Since the development of the entropy theory by Shannon in the late 1940s and the principle of maximum entropy (POME) by Jaynes in the late 1950s, there has been a proliferation of applications of entropy in a wide spectrum of hydrology $[16,17]$. Approximate entropy was used as a diagnostic and it showed that $A p E n$ had good computational efficiency and high robustness in characterizing the severity of structural defect [18]. Permutation entropy is useful in the presence of dynamical or observational noise [19]. These two methods are based on entropy theory, and they diagnose the abrupt point with the inside structure of the time series by using system control equation.

Approximate entropy $(A p E n)$ analysis is a method for evaluating dynamic variation in data series that is based on entropy theory. It is conceptually straightforward and can be calculated quickly. Moreover, it is not highly sensitive to noise in the analyzed data set and can reliably provide an overview of the studied system's properties. This section describes how the approach was adapted to analyze dynamic structural variation in runoff time series. The moving approximate entropy (M-ApEn) is a nonnegative scalar that is used to represent the complexity of a time series; the greater its value, the greater the complexity of the data set. For any time series of the form $\{u(i) ; i=1,2, \ldots, n\}$ together with an initial dimensionality of $m$ and a tolerance threshold $r$, the approximate entropy can be computed as follows.

(1) Construct a set of $m$-dimensional vectors:

$$
\begin{array}{r}
X(i)=[u(i), u(i+1), \ldots, u(i+m-1)], \\
(i=1,2, \ldots, n-m+1) .
\end{array}
$$

(2) Calculate the Euclidean distance between the vectors $X(i)$ and $X(j)$ :

$$
\begin{array}{r}
d[X(i), X(j)]=\max [|X(i+k)-X(j+k)|], \\
(k=0,1,2, \ldots, m-1) .
\end{array}
$$

(3) Determine the number of values of $i=1,2, \ldots, n-$ $m+1$ for which $d[X(i), X(j)]$ is less than $r$; this number is denoted by $C_{i}^{m}(r)$;

$$
C_{i}^{m}(r)=\text { number }\{d[X(i), X(j)] \leq r\} /(N-m+1) .
$$

(4) Compute the average value of the logarithm of $C_{i}^{m}(r)$ for all values of $i$; the resulting term is denoted by $\phi^{m}$ :

$$
\phi^{m}(r)=\frac{1}{N-m+1} \sum_{i=1}^{N-m+1} \ln C_{i}^{m}(r) .
$$

(5) Increase $m$ by 1 and repeat steps (1) to (4).

(6) By performing steps (1) to (5) iteratively, one obtains the approximate entropy time series:

$$
\operatorname{ApEn}(m, r)=\phi^{m}(r)-\phi^{m+1}(r) .
$$

Steps (1) to (6) reconstruct the $m$-dimensional sequence based on the degree of similarity between two points in terms of their values and position within the vector. Increases in the value of $m$ indicate an increased likelihood that there has been a shift to a new mean approximate entropy; the greater the increase, the greater the likelihood that there is a corresponding abrupt change in the underlying data set, and hence the greater its complexity. Differences in the ApEn value at different points in time can thus be used to keep the ability of self-similar state and divide the period covered by a data set into separate phases separated by abrupt transitions. The quantity computed in step (4) is the approximate entropy and is used in conjunction with values of $m$ and $r$ that can be obtained from the literature to compute the moving ApEn. In this work, the following values were selected for the moving approximate entropy analysis parameters: $m=2, r=0.1-$ $0.2 \sigma, L=365$ days, and $M=365$ days. The $\sigma$ value was taken to be the standard deviation of the original sequence, $u(i)$.

2.2. The Moving Permutation Entropy Test for Detecting Abrupt Changes. Permutation entropy is a metric that is based on entropy theory and can be used to characterize dynamic variation. In this work, a moving average of the permutation entropy was computed, to give a quantity that was termed the moving permutation entropy (M-PE) and was used to analyze the dynamic structural variation in the Lintong runoff series. The permutation entropy provides a measure of the complexity of a dataset and is computed using the following algorithm.

Given a one-dimensional hydrological time series $\{x(i), i=1,2, \ldots, n\}$, for any $x(i)$, phase space reconstruction will produce a one-dimensional vector:

$$
X(i)=[x(i), x(i+\tau), \ldots, x(i+(m-1) \tau)] .
$$

Here, $m$ and $\tau$ represent the embedding dimension and the delay time, respectively. 
If the $m$ th reconstruction components of $X(i)$, that is, $[x(i), x(i+\tau), \ldots, x(i+(m-1) \tau]$ are sorted in order of size, one obtains the following:

$$
\begin{array}{r}
{\left[x\left(i+\left(k_{1}-1\right)\right) \leq x\left(i+\left(k_{2}-1\right) \tau\right) \leq \cdots \leq x\left(i+\left(k_{p}-1\right) \tau\right],\right.} \\
1 \leq k \leq n-m+1 .
\end{array}
$$

In the sorting process, if $x\left(i+\left(k_{i 1}-1\right) \tau=x\left(i+\left(k_{i 2}-\right.\right.\right.$ $1) \tau)$, any vector $X(i)$ can be used to generate a sequence of the following form by means of $K$ sorting:

$$
B(t)=\left[k_{1}, k_{2}, \ldots, k_{t}\right], \quad 1 \leq t \leq n-m+1 .
$$

For each group, there are a total of $m$ ! Different permutation of the symbol sequence $\left[k_{1}, k_{2}, \ldots, k_{m}\right]$, and $B(t)=$ $\left[k_{1}, k_{2}, \ldots, k_{m}\right]$ denotes one of these sequences. Probability analysis can be used to associate each sequence with a set of probabilities for the $n-m+1$ group: $P_{1}, P_{2}, \ldots, P_{l}$.

According to Shannon, information entropy can be calculated for such a set of probabilities, $P_{1}, P_{2}, \ldots, P_{m-p+1}$, as follows:

$$
H_{p}(m)=-\sum_{i=1}^{l} P_{i} \ln P_{i} .
$$

Theoretically, when $P_{i}=1 / m !, H_{P}(m)$ reaches a maximum of $\ln (m !)$. In practice, $H_{P}(m)$ is usually normalized against $\ln (n-m+1)$ :

$$
0 \leq H_{p}=\frac{H_{P}(m)}{\ln (m !)} \leq 1 .
$$

$\mathrm{HP}$ is the PE value, and its size reflects the degree of randomness in the studied time series. The lower the value of HP, the more regular (i.e., the less complex) the sequence. Conversely, the greater the HP value, the more random (i.e., complex) the sequence.

At present, there is no established method for selecting an appropriate subsequence length $(n)$ or embedding dimension $(m)$. The influence of the subsequence length and the $m$ value on the outcome of the analysis has been discussed at length in the literature $[19,20]$. It is known that if an excessively low subsequence length is used, the identification of abrupt changes in the time series becomes unreliable, and the reconfigurable vector containing too little information will make the PE algorithm invalid. Based on the literature results [13], the following values for these crucial parameters were adopted in the analyses presented below: a subsequence of length $(n)$ of 5 years, a sliding step length $L$ of 1 day, and an embedding dimensionality $(m)$ of 5 .

\section{Study Area}

The Wei River is the largest tributary of the Yellow River. Its origin is in Niaoshu Hill in Weiyuan County of Gansu province. The Wei River basin covers parts of the Gansu, Ningxia, and Shaanxi provinces, and it joins the Yellow River in Tongguan County of Shaanxi province (Figure 1). The basin's catchment area is $134800 \mathrm{~km}^{2}$, and the river runs for $818 \mathrm{~km}$. Its upper reaches, which account for around $70 \%$ of its total length, are primarily located in hilly Loess regions, at elevations of 2400 to $1200 \mathrm{~m}$. The lower $10 \%$ of its length lies in river valleys at elevations of $1700 \mathrm{~m}-900 \mathrm{~m}$. The midreaches of the Wei River lie in the northern Loess Plateau of northern Shaanxi province, at elevations of 2000$900 \mathrm{~m}$, and the river plays a central role in Loess deposition. It joins the Yellow River on the alluvial plains of the Guanzhong basin, whose eastern regions have an elevation of $700 \mathrm{~m}-$ $800 \mathrm{~m}$ that falls to $500-320 \mathrm{~m}$ on moving westwards. The Qin mountain range, which has many peaks above $2000 \mathrm{~m}$, is located to the south of the Wei River basin. The river's basin covers both arid and humid regions, with most of the precipitation falling in the north; the mountainous regions and the valleys receive comparatively little rainfall. The majority of the area's precipitation occurs in July and August, with December and January being the driest months of the year. The period between July and October typically accounts for around $60 \%$ of the area's total annual precipitation. The basin has a continental monsoon climate, with the total rainfall and temperature gradually decreasing on moving from the southeast to the northwest. The average annual evaporation from wet surfaces in the basin is $660 \mathrm{~mm}-$ $1600 \mathrm{~mm}$; the rate of evaporation is lowest in December and highest in June or July. The period between July and October accounts for $46 \%-58 \%$ of the region's total annual evaporation. The Wei River basin has many tributaries, most of which join the river on its south bank. However, the larger tributaries generally join the main river through the north bank, producing a fan-shaped basin. The basin has 14 tributaries and a catchment area of more than $100,000 \mathrm{~km}^{2}$. Most of the tributaries on the north bank originate in the Loess Hills and the Loess Plateau. They are generally longer than the southern tributaries, flow over shallower slopes, and have greater sediment loads. The tributaries on the south bank originate in the Qin mountains. They tend to be short and fast flowing, with steep slopes, high runoff volumes, and comparatively low sediment concentrations. The Lintong station is located in the river's downstream region and covers a drainage area of $97,300 \mathrm{~km}^{2}$, which corresponds to $88.8 \%$ of the river's total drainage area (excluding the Beiluohe basin).

\section{Data}

Daily streamflow data acquired at the Lintong hydrological station $\left(34^{\circ} 26^{\prime} \mathrm{N}, 109^{\circ} 12^{\prime} \mathrm{E}\right)$ during the period from 1961 to 2006 were obtained from the Bureau of Hydrology and Water Resources of Shaanxi province. The first measurements in the data series were acquired in January 1961. Lintong station is located downstream of the Wei River with drainage area of $97299 \mathrm{~km}^{2}$. The locations of the hydrological stations in the Wei River Basin are shown in Figure 2. As seen from Figure 3, annual runoff stays at an almost constant level after some sudden upward jumps are recorded. The maximum annual runoff corresponding to differences is 158.21 billion $\mathrm{m}^{3}$. The minimum and maximum were recorded as 19.61 billion $\mathrm{m}^{3}$ 


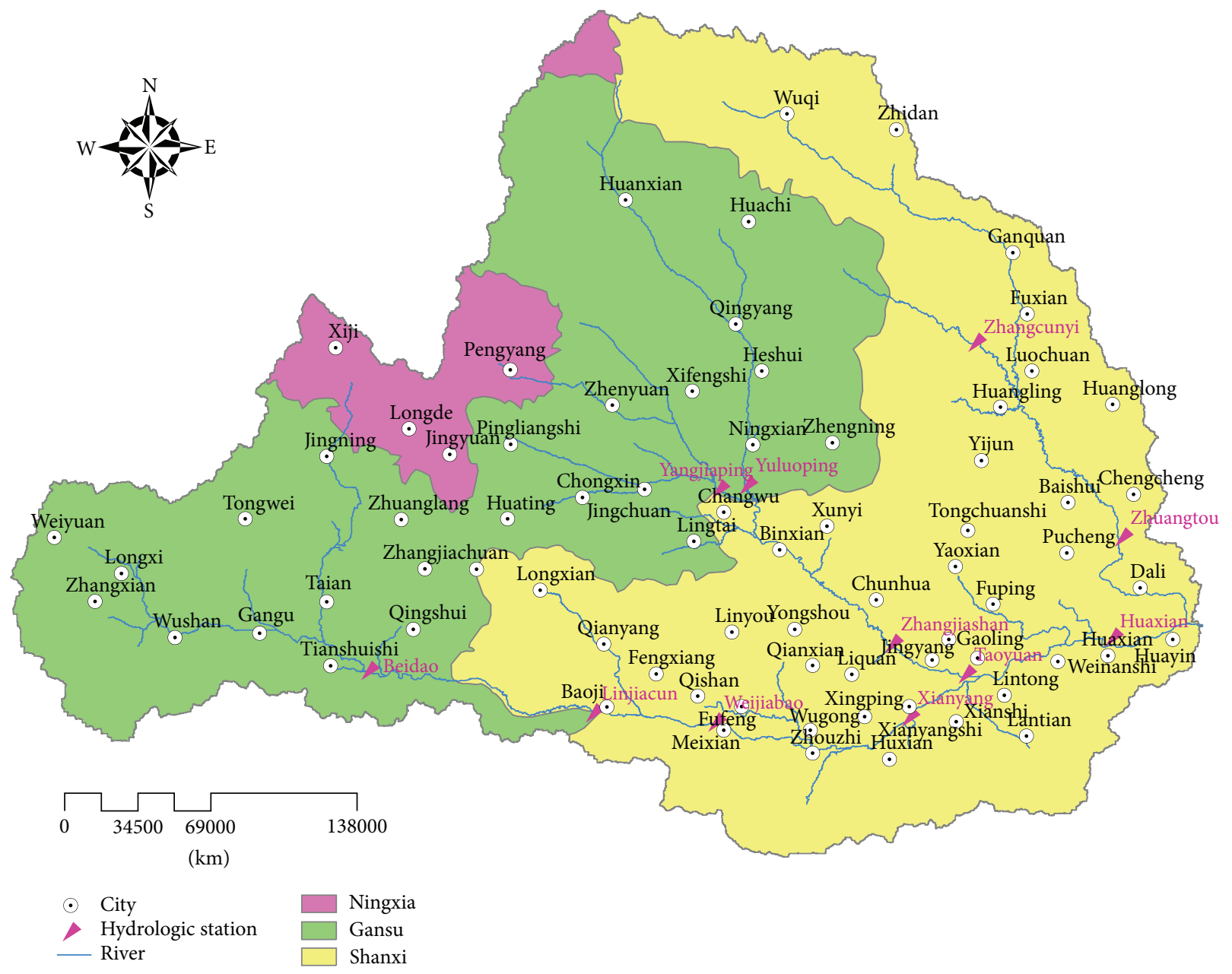

FIgURE 1: Map of the Wei River basin.

and 1.82 billion $\mathrm{m}^{3}$. During observation period mean runoff is 6.59 billion $\mathrm{m}^{3}$.

The hydrological variables considered in this work were the mean annual flow, the mean monthly flow, the maximum annual flow, the minimum annual flow, the timing of hydrologic events, maximum, and minimum flows on a daily, 3-day, 7-day, 30-day, and 90-day basis. These variables were selected because they are widely used in comparing flows and engineering applications. Variables associated with minimum flow were evaluated over four separate periods, that is, 1961-1971, 1972-1982, 1983-2001, and 2002-2006.

\section{Analysis and Result}

5.1. Results of the Moving Approximate Entropy Test. The M-ApEn method was used to detect abrupt changes in the Lintong station daily runoff time series. In this analysis, the value of $m$ was chosen to be 2 , the allowed deviation $(r)$ was $=0.15 \sigma$, the moving step length $L$ was $365 \mathrm{~d}$, and the subsequence length $M$ was also $365 \mathrm{~d}$. Time points at which the difference between the ApEn value and the moving average $A p E n$ was greater than $20 \%$ of the moving average were characterized as change points; that is, points at which an abrupt change had occurred. The calculated ApEn values for the Lintong Station daily runoff time series are shown in Figure 4. The ApEn value changes are clearly shown in Figure 1. The results show the four stages of abrupt change; appeared in 1972, 1983, and 2002.

(1) The first change point occurs in 1972, at which the difference between the ApEn value and the moving average is $22.9 \%$ of the moving average.

(2) The second change point occurs in 1983, at which the difference between the ApEn value and the moving average is $24.2 \%$ of the moving average.

(3) The third change point occurs in 2002 , at which the difference between the ApEn value and the moving average is $34.1 \%$ of the moving average.

5.2. Results of the Moving Permutation Entropy Test. The M$\mathrm{PE}$ method was used to analyze the daily runoff time series for the Lintong Station and to identify abrupt changes in the daily runoff volume. The parameter values used in the analysis were as follows: $m=5$, lag time $=1 \mathrm{~d}, L=1 \mathrm{~d}$, and $M=5 \mathrm{a}$. 


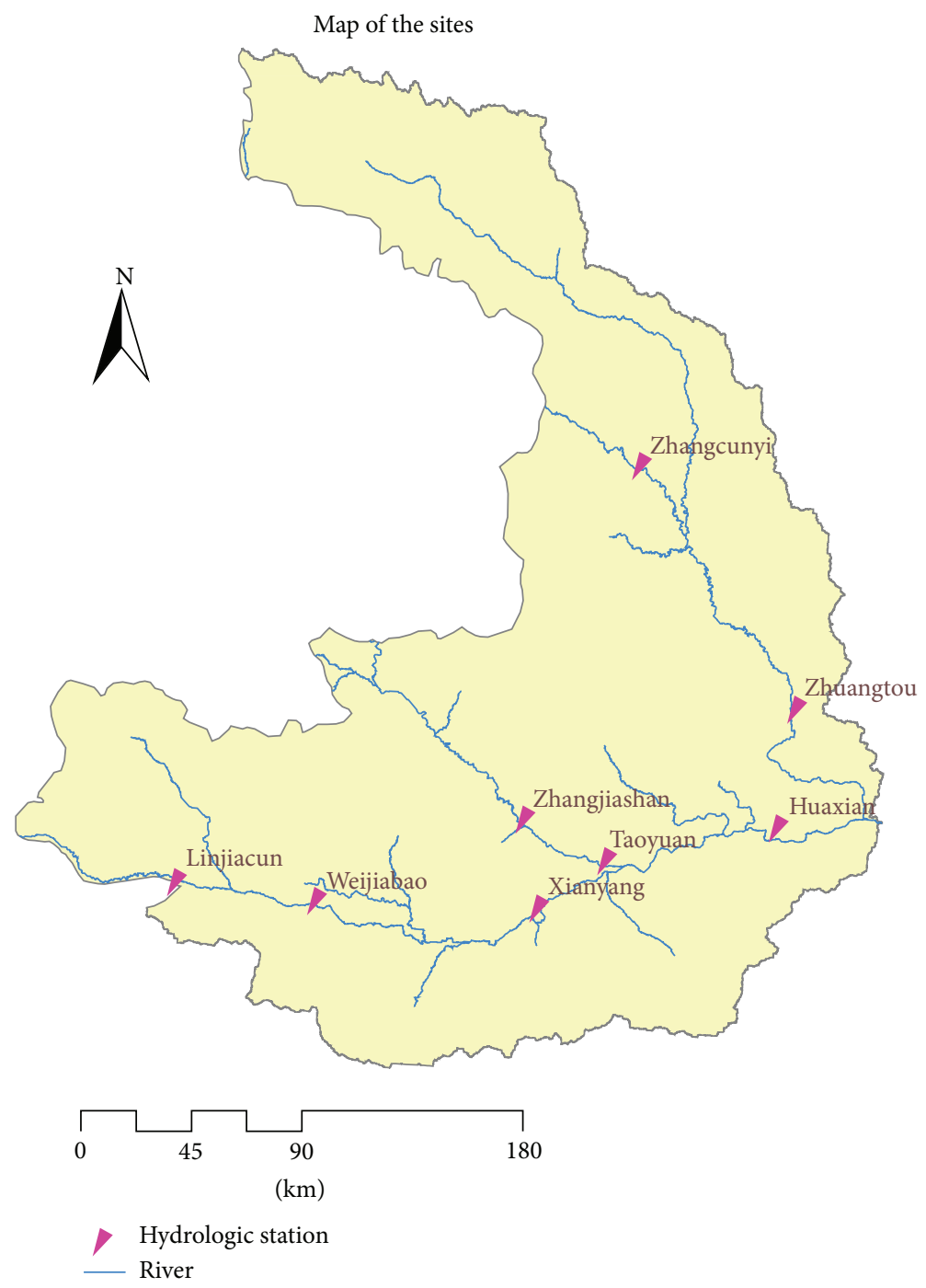

FIGURE 2: The locations of the hydrological monitoring stations in the Wei River basin.

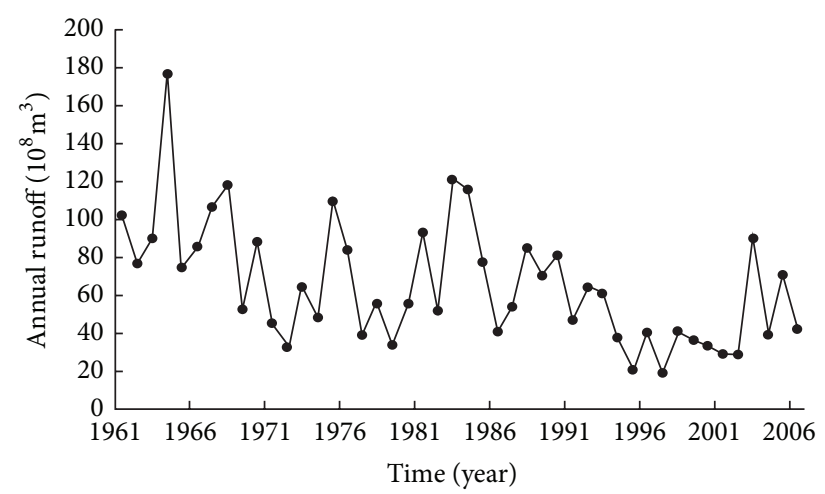

FIGURE 3: The annual daily runoff of Lintong station in the Wei River basin.

The results obtained are shown in Figure 5. Inspection of this figure clearly shows that abrupt changes in the PE value occur

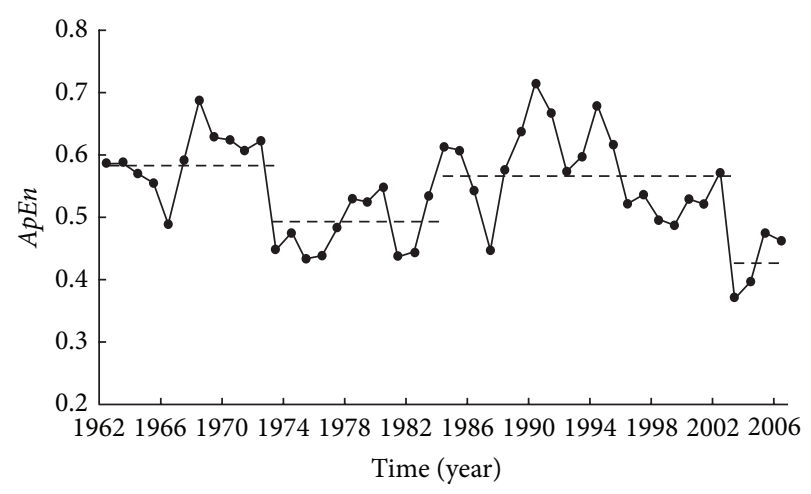

FIGURE 4: Calculated ApEn values based on the daily runoff series for the Lintong station in the Wei River.

in the early nineteen seventies and at the beginning of the twenty-first century. 


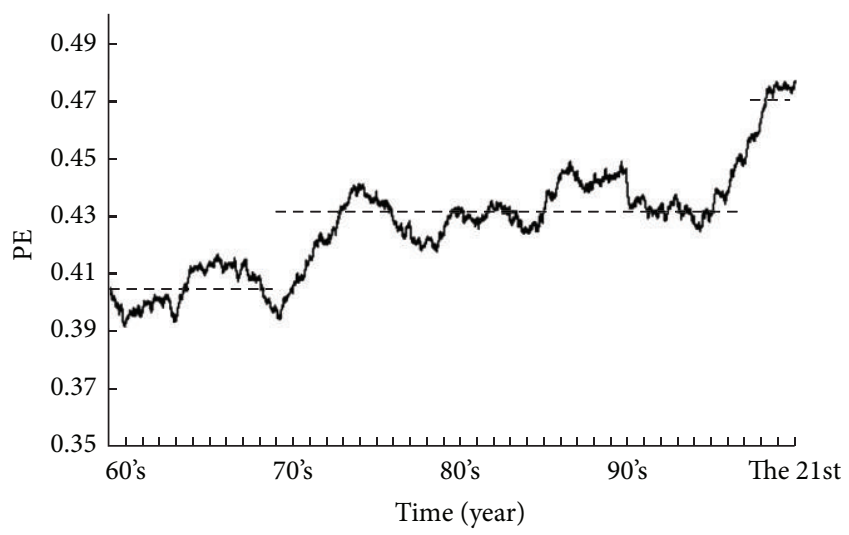

FIgURE 5: Calculated PE values based on the daily runoff for the Lintong station in the Wei River basin.

The points of abrupt change in daily runoff volume identified using the M-ApEn method are 1972, 1983, and 2002. Using the M-PE method, abrupt changes were detected in the early 1970s and at the beginning of the 21st century. Considering the results of two methods, the abrupt changes are 1972,1983 , and 2002.

\section{Discussion and Conclusions}

6.1. Results of Hydrological Characteristics. Based on the results obtained in the M-ApEn and M-PE analyses, the runoff time series can be divided into four separate periods: 1961-1971, 1972-1982, 1983-2001, and 2002-2006.

For each of these periods, the values of selected hydrological variables measured at the Lintong Station were compared to those in the preceding period in an attempt to determine whether the abrupt changes detected by analyzing the daily runoff volume were associated with changes in other hydrological properties. The following noteworthy changes were identified.

(1) The mean annual runoff volume during the second period was 6.071 billion $\mathrm{m}^{3}$, compared to 8.74 billion $\mathrm{m}^{3}$ during the first period, representing a decrease of $31 \%$. The mean annual runoff in the third period was 5.515 billion $\mathrm{m}^{3}$, which represents a decrease of $9 \%$ relative to the second period. The mean annual runoff in the fourth period was 6.057 billion $\mathrm{m}^{3}$, which corresponds to an increase of $10 \%$ relative to the third period. Overall, the most pronounced change in the mean annual runoff volume occurred between 1961-1971 and 1972-1982, corresponding to the abrupt change identified in 1972 in the M-ApEn analysis and in the early 1970s in the $\mathrm{M}-\mathrm{PE}$ analysis. The results of the annual daily runoff volume measured at the Lintong station in the Wei River basin are shown in Figure 6.

(2) During the first period (1961-1971), the total runoff volumes in all months other than August were lower than those in the same months during the second period (1972-1982). For the months of March, April,

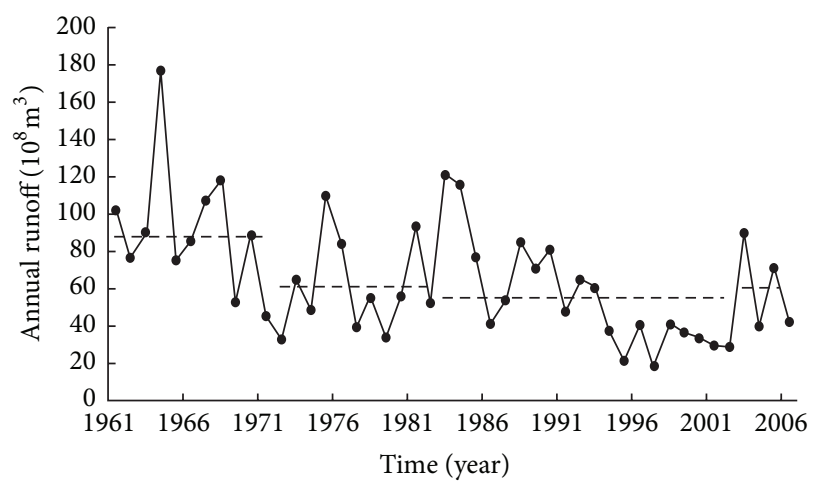

FIGURE 6: The annual daily runoff volume measured at the Lintong station in the Wei River basin.

May, and June, the total runoff volumes during the second period were less than half those measured during the first period. The monthly runoff volumes for the third period were generally greater than those for the second period. This was especially true in June, for which the mean runoff volume during the third period was $162 \%$ of that for the second period. The June runoff volume increased again during the fourth period, when it was $111 \%$ greater than that for the third period. The results of total monthly runoff volumes measured at the Lintong station in the Wei River basin are shown in Table 1.

(3) The maximum and minimum runoff volumes during the second period were generally lower than those during the first period; while maxl increased very slightly, the other maximum and minimum values fell by between $3 \%$ and $66 \%$. There were very substantial changes between the second and third periods: the maximum values for the third period were all slightly lower than those for the second, whereas the minimum runoff volumes were all substantially greater. All of the maximum and minimum runoff volumes measured during the fourth period were greater than the corresponding values for the third period; the greatest change occurred for Min3, which increased by $44 \%$. The results of minimum and maximum runoff volumes calculated over periods of $1,3,7,30$, and 90 days for the Lintong station in the Wei River basin are shown in Table 2 .

6.2. Attribution of Abrupt Changes. The variation of runoff series is primarily due to climate change (reductions in precipitation) and increases in human activity. The present study shows that the precipitation changes are strongly impacted with the climate [15]; the climate strongly controlled the runoff conditions, and human activities (as water conservancy and water and soil conservation) are closely related to the runoff [21].

6.2.1. Reduced Precipitation. Inspection of Table 3 clearly shows that, compared with the 1970s, the average annual 
TABLE 1: Total monthly runoff volumes measured at the Lintong station in the Wei River basin.

\begin{tabular}{|c|c|c|c|c|c|c|c|c|c|c|}
\hline Month & $\begin{array}{l}\text { First stage } \\
/\left(10^{8} \mathrm{~m}^{3}\right)\end{array}$ & $\begin{array}{c}\text { Second } \\
\text { stage } \\
/\left(10^{8} \mathrm{~m}^{3}\right)\end{array}$ & $\begin{array}{c}\text { Mean } \\
\text { difference } \\
/\left(10^{8} \mathrm{~m}^{3}\right)\end{array}$ & $\begin{array}{l}\text { Rate of } \\
\text { migration }\end{array}$ & $\begin{array}{c}\text { Third } \\
\text { stage } \\
/\left(10^{8} \mathrm{~m}^{3}\right)\end{array}$ & $\begin{array}{c}\text { Mean } \\
\text { difference } \\
\left(10^{8} \mathrm{~m}^{3}\right)\end{array}$ & $\begin{array}{l}\text { Rate of } \\
\text { migration }\end{array}$ & $\begin{array}{c}\text { Fourth } \\
\text { stage } \\
/\left(10^{8} \mathrm{~m}^{3}\right)\end{array}$ & $\begin{array}{c}\text { Mean } \\
\text { difference } \\
/\left(10^{8} \mathrm{~m}^{3}\right)\end{array}$ & $\begin{array}{c}\text { Rate of } \\
\text { migration }\end{array}$ \\
\hline January & 2.31 & 1.24 & -1.07 & $-46 \%$ & 1.44 & 0.2 & $16 \%$ & 1.95 & 0.51 & $35 \%$ \\
\hline February & 2.33 & 1.36 & -0.97 & $-42 \%$ & 1.52 & 0.16 & $12 \%$ & 1.94 & 0.42 & $28 \%$ \\
\hline March & 3.96 & 1.73 & -2.23 & $-56 \%$ & 2.36 & 0.63 & $36 \%$ & 2.38 & 0.02 & $1 \%$ \\
\hline April & 7.24 & 2.92 & -4.32 & $-60 \%$ & 3.51 & 0.59 & $20 \%$ & 2.67 & -0.84 & $-24 \%$ \\
\hline May & 10.19 & 4.19 & -6 & $-59 \%$ & 4.95 & 0.76 & $18 \%$ & 3.76 & -1.19 & $-24 \%$ \\
\hline June & 4.63 & 1.98 & -2.65 & $-57 \%$ & 5.19 & 3.21 & $162 \%$ & 11 & 5.77 & $111 \%$ \\
\hline July & 11.06 & 8.4 & -2.66 & $-24 \%$ & 8.7 & 0.3 & $4 \%$ & 6.83 & -1.87 & $-21 \%$ \\
\hline August & 7.69 & 9.67 & 1.98 & $26 \%$ & 8.1 & -1.57 & $-16 \%$ & 12.2 & 4.11 & $51 \%$ \\
\hline September & 17.11 & 13.94 & -3.17 & $-19 \%$ & 8.02 & -5.92 & $-42 \%$ & 11.4 & 3.42 & $43 \%$ \\
\hline October & 14.51 & 9.34 & -5.17 & $-36 \%$ & 7.33 & -2.01 & $-22 \%$ & 12.5 & 5.16 & $70 \%$ \\
\hline November & 7.55 & 4.32 & -3.23 & $-43 \%$ & 3.81 & -0.51 & $-12 \%$ & 4 & 0.19 & $5 \%$ \\
\hline December & 3.77 & 1.68 & -2.09 & $-55 \%$ & 1.7 & 0.02 & $1 \%$ & 2.59 & 0.89 & $52 \%$ \\
\hline
\end{tabular}

TABLE 2: Minimum and maximum runoff volumes calculated over periods of 1, 3, 7, 30, and 90 days for the Lintong station in the Wei River basin.

\begin{tabular}{lcccccccccc}
\hline Value & $\begin{array}{c}\text { First } \\
\text { stage } \\
/\left(10^{8} \mathrm{~m}^{3}\right)\end{array}$ & $\begin{array}{c}\text { Second } \\
\text { stage } \\
/\left(10^{8} \mathrm{~m}^{3}\right)\end{array}$ & $\begin{array}{c}\text { Mean } \\
\text { difference } \\
/\left(10^{8} \mathrm{~m}^{3}\right)\end{array}$ & $\begin{array}{c}\text { Rate of } \\
\text { migration }\end{array}$ & $\begin{array}{c}\text { Third } \\
\text { stage } \\
/\left(10^{8} \mathrm{~m}^{3}\right)\end{array}$ & $\begin{array}{c}\text { Mean } \\
\text { difference } \\
\left(10^{8} \mathrm{~m}^{3}\right)\end{array}$ & $\begin{array}{c}\text { Rate of } \\
\text { migration }\end{array}$ & $\begin{array}{c}\text { Fourth } \\
\text { stage } \\
/\left(10^{8} \mathrm{~m}^{3}\right)\end{array}$ & $\begin{array}{c}\text { Mean } \\
\text { difference } \\
/\left(10^{8} \mathrm{~m}^{3}\right)\end{array}$ & $\begin{array}{c}\text { Rate of } \\
\mathrm{migration}^{2}\end{array}$ \\
\hline $\max 1$ & 3120.00 & 3148.09 & 28.09 & $1 \%$ & 2091.37 & -1056.72 & $-34 \%$ & 2272.40 & 181.03 & $9 \%$ \\
$\max 3$ & 6828.09 & 6597.00 & -231.09 & $-3 \%$ & 4566.26 & -2030.74 & $-31 \%$ & 5175.60 & 609.34 & $13 \%$ \\
$\max 7$ & 10865.64 & 11735.64 & 870.00 & $8 \%$ & 7263.49 & -4472.15 & $-38 \%$ & 8448.60 & 1185.11 & $16 \%$ \\
$\max 30$ & 26433.18 & 25706.53 & -726.65 & $-3 \%$ & 17245.20 & -8461.33 & $-33 \%$ & 18460.14 & 1214.94 & $7 \%$ \\
$\max 90$ & 52345.23 & 44413.50 & -7931.73 & $-15 \%$ & 34207.21 & -10206.29 & $-23 \%$ & 35926.12 & 1718.91 & $5 \%$ \\
$\min 1$ & 23.10 & 7.98 & -15.12 & $-65 \%$ & 20.67 & 12.69 & $159 \%$ & 29.36 & 8.69 & $42 \%$ \\
$\min 3$ & 74.73 & 26.02 & -48.71 & $-65 \%$ & 65.14 & 39.12 & $150 \%$ & 93.78 & 28.64 & $44 \%$ \\
$\min 7$ & 221.61 & 74.32 & -147.29 & $-66 \%$ & 170.53 & 96.21 & $129 \%$ & 241.06 & 70.53 & $41 \%$ \\
$\min 30$ & 1578.29 & 703.96 & -874.33 & $-55 \%$ & 1102.14 & 398.19 & $57 \%$ & 1472.88 & 370.74 & $34 \%$ \\
$\min 90$ & 8949.95 & 4311.14 & -4638.81 & $-52 \%$ & 5602.16 & 1291.02 & $30 \%$ & 5665.44 & 63.28 & $1 \%$ \\
\hline
\end{tabular}

precipitation is all reduced in every stages. The mean annual precipitation volume during the 1972 1982 period was $340.75 \mathrm{~mm}$, compared to $359.95 \mathrm{~mm}$ during the $1960 \sim$ 1971 period, representing a decrease of $5 \%$. The mean annual precipitation in the 1983 2001 period was $31.79 \mathrm{~mm}$, which represents a decrease of $9 \%$ relative to the first period. The mean annual precipitation in the 1983 2001 period was $10.57 \mathrm{~mm}$, which represents a decrease of $3 \%$ relative to the first period.

For 1960 1971, 1972 1982, and 1983 2001 periods. The mean annual precipitation volumes were all decreased compared to those in the preceding period. The rate of the decrease from 1983 to 2001 was $3.70 \%$ which is smaller than before, and the rate of 2002 2006 represents an increase of $6.47 \%$ relative to $1983-2001$. Hence, the precipitation variation is one of the most important factors for runoff change.

6.2.2. Increased Water Conservancy. A large number of water conservancy projects have been built in the early 1970s, such as Yangmaowan Reservoir (1970, with a total storage capacity of 120 million $\mathrm{m}^{3}$ ), Shihmen Reservoir (1970, with a total storage capacity of 120 million $\mathrm{m}^{3}$ ), Lin Gao Reservoir (1971, with a total capacity of 0.33 million $\mathrm{m}^{3}$ ) and some irrigation districts as Hengshui River irrigation (effective irrigation area of $9407 \mathrm{hm}^{2}$ ), Baojixia irrigation (effective irrigation area of $188,553 \mathrm{hm}^{2}$ ), Wool Bay irrigation district (effective irrigation area of $16,000 \mathrm{hm}^{2}$ ), of Lin Gao Irrigation (effective irrigation area of 5733). The mean annual runoff in 19721982 was 6.07 billion $\mathrm{m}^{3}$, which represents a decrease of 2.67 billion $\mathrm{m}^{3}$ relative to $1960-1971$ period. The human activities are significantly impacting factor on runoff.

A large number of water conservancy projects were built in the early 1980s, some reservoirs as Shitou River Reservoir (1981, with a total capacity of 147 million $\mathrm{m}^{3}$ ), Taoqupo reservoir (1980, with a total capacity of 0.57 million $\mathrm{m}^{3}$ ) and some irrigation districts as Dongfanghong irrigation (effective irrigation area of $55800 \mathrm{hm}^{2}$ ). The mean annual runoff in 1983-2001 was 5.51 billion $\mathrm{m}^{3}$, which represents a decrease of 0.56 billion $\mathrm{m}^{3}$ relative to $1972-1983$ period. 
TABLE 3: The annual precipitation volume measured at the Lintong station in the Wei River basin.

\begin{tabular}{lccccc}
\hline \multirow{2}{*}{ Period } & \multirow{2}{*}{ Mean/(mm) } & \multicolumn{2}{c}{ Compared to the first period } & \multicolumn{2}{c}{ Compared to the preceding period } \\
& & Mean difference/ $(\mathrm{mm})$ & Rate of migration & Mean difference/(mm) & \\
Rate of migration
\end{tabular}

The cumulative effects of human activities after 1990s, such as industrial and agricultural water consumption, soil and water conservation water consumption and evaporation continue to increase, Groundwater level and the water consumption of the national economy were significantly decreased. The mean annual runoff in 2002-2006 was 6.06 billion $\mathrm{m}^{3}$, which represents an increase of 0.54 billion $\mathrm{m}^{3}$ relative to 1983-2001 period.

6.3. Conclusion. Two methods for the identification of abrupt changes in time series-moving approximate entropy analysis and moving permutation entropy analysis-were used to study the variation of 46-year daily runoff series at the Lintong station in the Wei River basin. Both analyses indicated that abrupt changes occurred in the early 1970s (1972) and at the start of the 21st century (2002); in addition, the moving approximate entropy analysis revealed a third abrupt change that is estimated to have occurred in 1983. These so-called change points were used to separate the 46-year period covered by the runoff volume data set into four separate periods, and the mean values of selected hydrological variables within these periods were compared to evaluate the impact of these abrupt changes. Notable differences between the periods were identified in terms of the total annual runoff, total monthly runoff volumes, and the maximum and minimum runoff volumes over selected periods of time. The changes associated with the transition between the first and second periods in 1972 were especially pronounced. Overall, the observed changes in the selected hydrological variables are consistent with the abrupt changes identified using the two new analytical methods, which suggests that both of the new methods are useful for analyzing runoff series and identifying points of abrupt change. The attribution of abrupt change at the Lintong runoff series is primarily due to the reduced precipitation, increased human activities, increased water consumption of industry and agriculture, significantly decreased groundwater table, and increased evaporation.

\section{Acknowledgments}

Natural Science Foundation of China (no. 51190093, 51179148, 51179149), National Key Basic Research 973 of China (no. 2012CB417003), Governmental public industry research special funds for projects (no. 201101043), and Program for New Century Excellent Talents in University. Constructive comments from reviewers are gratefully acknowledged.

\section{References}

[1] A. M. Fowler and K. J. Hennessy, "Potential impacts of global warming on the frequency and magnitude of heavy precipitation," Natural Hazards, vol. 11, no. 3, pp. 283-303, 1995.

[2] IPCC, "Intergovernmental Panel on Climate Change," 2007.

[3] F. J. Wentz, L. Ricciardulli, K. Hilburn, and C. Mears, "How much more rain will global warming bring?" Science, vol. 317, no. 5835, pp. 233-235, 2007.

[4] K. E. Trenberth, "Conceptual framework for changes of extremes of the hydrological cycle with climate change," Climatic Change, vol. 42, no. 1, pp. 327-339, 1999.

[5] D. R. Easterling, G. A. Meehl, C. Parmesan, S. A. Changnon, T. R. Karl, and L. O. Mearns, "Climate extremes: observations, modeling, and impacts," Science, vol. 289, no. 5487, pp. 20682074, 2000.

[6] T. G. Huntington, "Evidence for intensification of the global water cycle: review and synthesis," Journal of Hydrology, vol. 319, no. 1-4, pp. 83-95, 2006.

[7] W. Fengying, Modern Technology of Statistics, Diagnosis and Forecast for Climate, China Meteorological Press, Beijing, China, 1999.

[8] W. Hou, G. Feng, W. Dong, and J. Li, “Technique for distinguishing dynamical species in the temperature time series of north China," Acta Physica Sinica, vol. 55, no. 5, pp. 2663-2668, 2006 (Chinese).

[9] G. H. Huang, C. P. Ou, and J. Xia, "Study of watershed hydrological spatio-temporal variability analysis based on information entropy," Journal of Dalian University of Technology, vol. 46, no. zl, pp. 168-173, 2006 (Chinese).

[10] S. M. Pincus, "Approximate entropy as a measure of system complexity," Proceedings of the National Academy of Sciences of the United States of America, vol. 88, no. 6, pp. 2297-2301, 1991.

[11] Q. Wang and Z. Zhang, "The research of detecting abrupt climate change with approximate entropy," Acta Physica Sinica, vol. 57, no. 3, pp. 1976-1983, 2008 (Chinese).

[12] W. He, Q. Wu, W. Zhang, Q. Wang, and Y. Zhang, "Comparison of characteristics of moving detrended fluctuation analysis with that of approximate entropy method in detecting abrupt dynamic change," Acta Physica Sinica, vol. 58, no. 4, pp. 28622871, 2009 (Chinese).

[13] W. Hou, G. L. Feng, W. J. Dong, and J. P. Li, “Technique for distinguishing dynamical species in the temperature time series of north China," Acta Physica Sinica, vol. 55, no. 5, pp. 26632668, 2006 (Chinese).

[14] L. R. Beard, Statistical Methods in Hydrology, DTIC Document, 1962.

[15] V. P. Singh, "The use of entropy in hydrology and water resources," Hydrological Processes, vol. 11, no. 6, pp. 587-626, 1997. 
[16] N. B. Harmancioglu, V. P. Singh, and N. Alpaslan, "Versatile uses of the entropy concept in water resources," in Entropy and Energy Dissipation in Water Resources, V. P. Singh and M. Fiorentino, Eds., pp. 91-117, Kluwer Academic, Dordrecht, 1992.

[17] D. Koutsoyiannis, "Uncertainty, entropy, scaling and hydrological statistics. 1. Marginal distributional properties of hydrological processes and state scaling/Incertitude, entropie, effet d'échelle et propriétés stochastiques hydrologiques. 1. Propriétés distributionnelles marginales des processus hydrologiques et échelle d'état," Hydrological Sciences Journal, vol. 50, no. 3, 2005.

[18] R. Yan and R. X. Gao, "Approximate entropy as a diagnostic tool for machine health monitoring," Mechanical Systems and Signal Processing, vol. 21, no. 2, pp. 824-839, 2007.

[19] C. Bandt, G. Keller, and B. Pompe, "Entropy of interval maps via permutations," Nonlinearity, vol. 15, no. 5, pp. 1595-1602, 2002.

[20] Y. Cao, W. W. Tung, J. B. Gao, V. A. Protopopescu, and L. M. Hively, "Detecting dynamical changes in time series using the permutation entropy," Physical Review E, vol. 70, no. 4, part 2, Article ID 046217, 7 pages, 2004.

[21] L. J. Li, L. Zhang, H. Wang et al., "Assessing the impact of climate variability and human activities on streamflow from the Wuding River basin in China," Hydrological Processes, vol. 21, no. 25, pp. 3485-3491, 2007. 


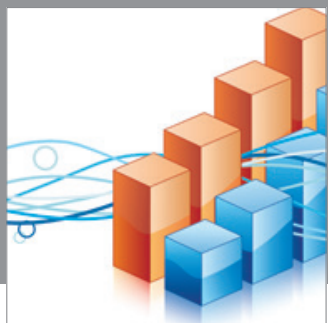

Advances in

Operations Research

mansans

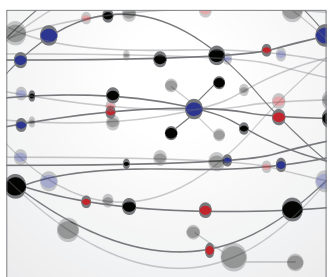

The Scientific World Journal
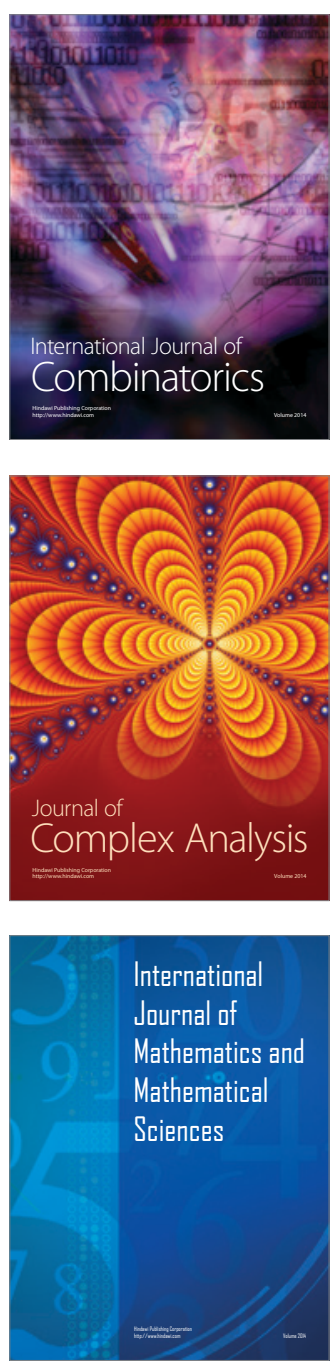
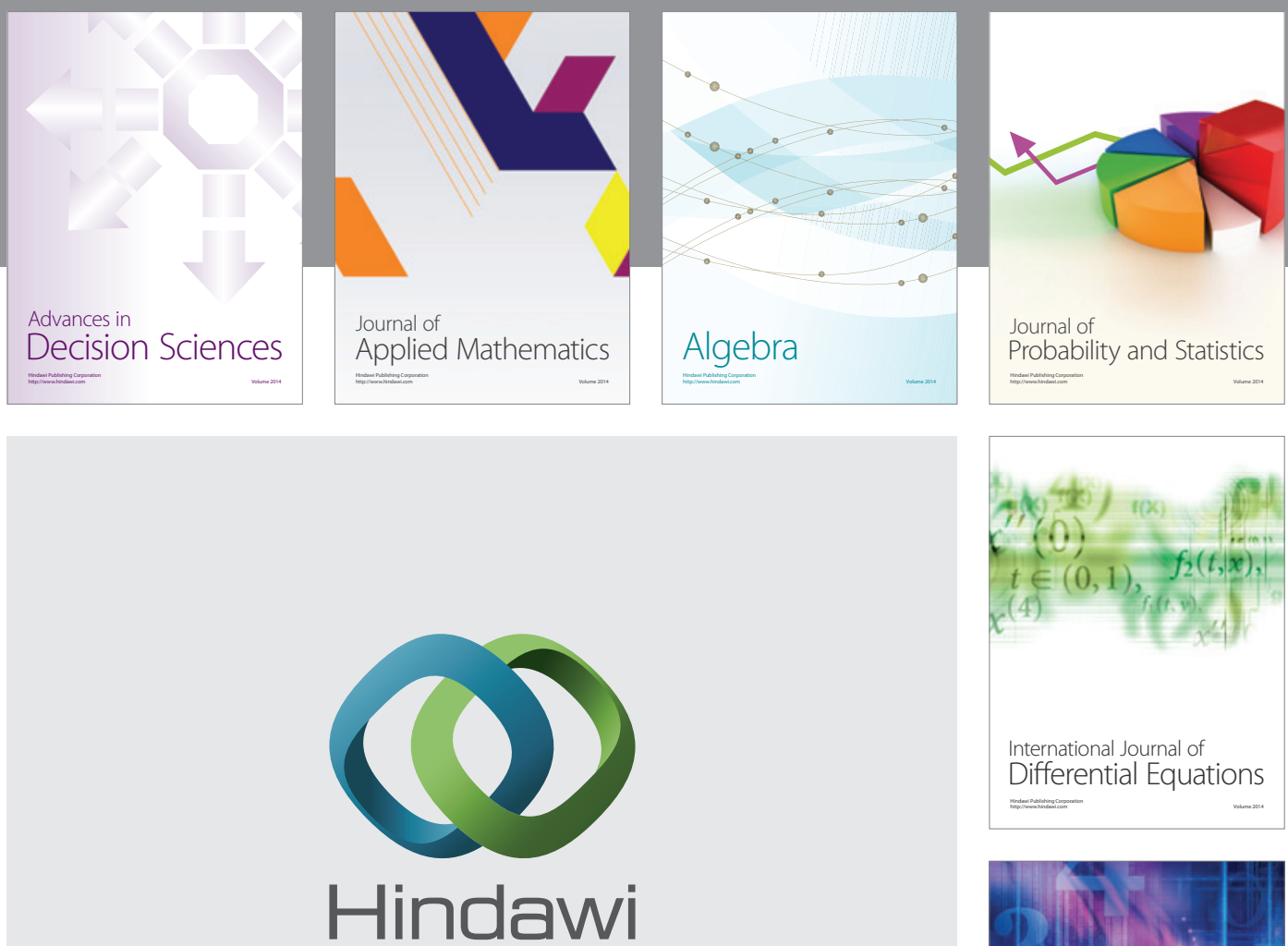

Submit your manuscripts at http://www.hindawi.com
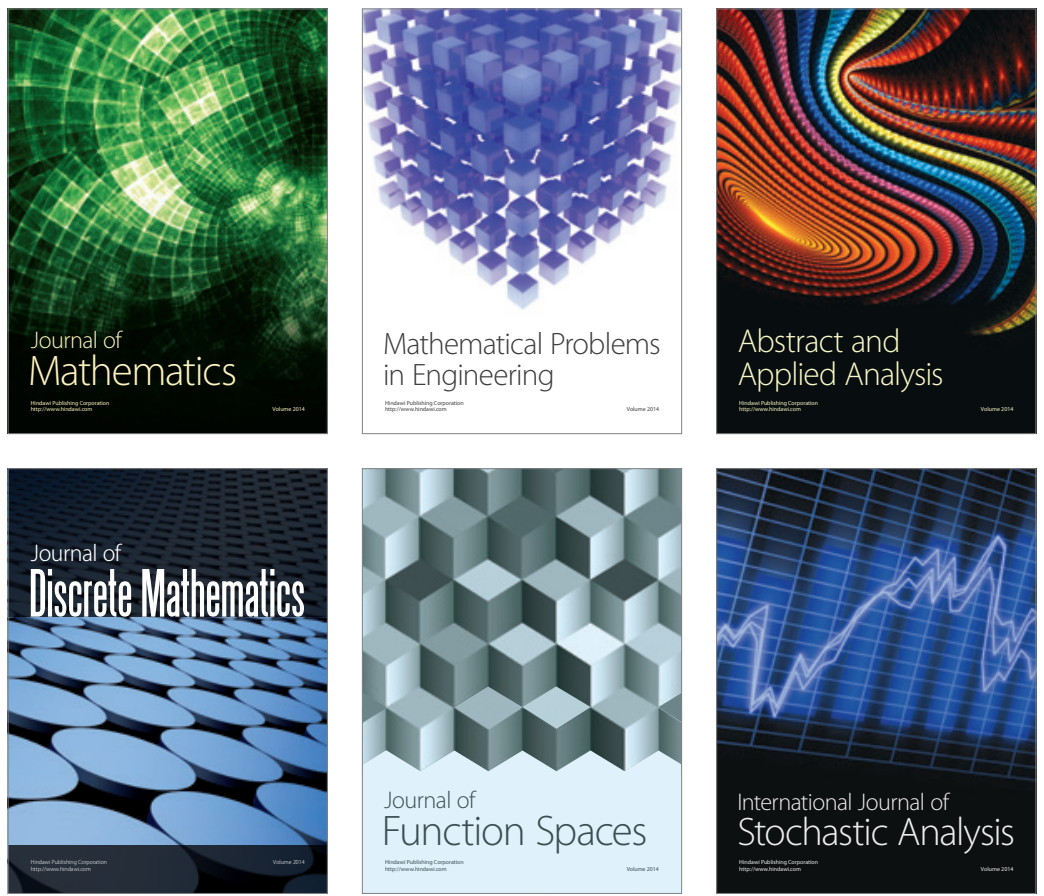

Journal of

Function Spaces

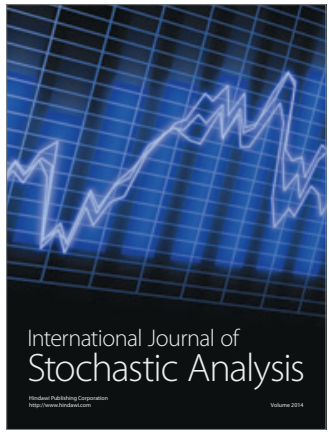

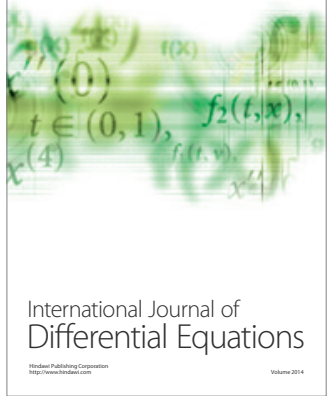
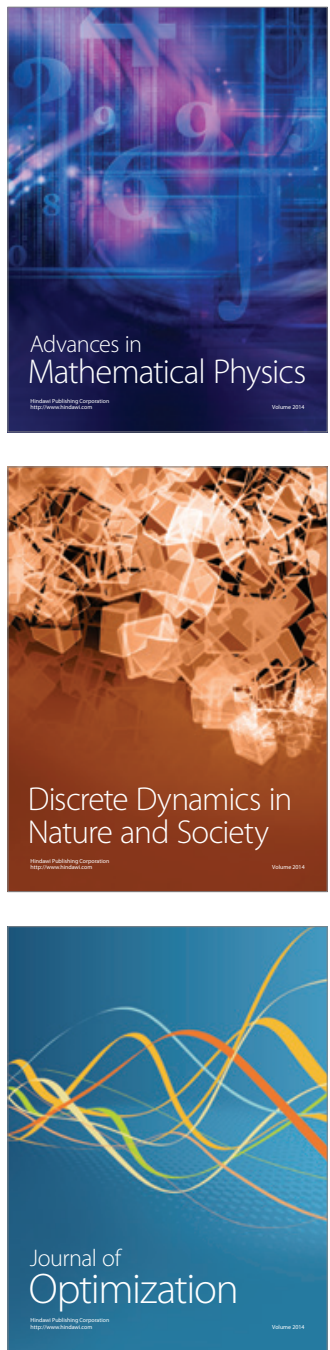